\title{
BMJ Open Protein supplementation versus standard feeds in underweight critically ill children: a pilot dual-centre randomised controlled trial protocol
}

To cite: Wong JJM, Ong JSM, Ong C, et al. Protein supplementation versus standard feeds in underweight critically ill children: a pilot dualcentre randomised controlled trial protocol. BMJ Open 2022;12:e047907. doi:10.1136/ bmjopen-2020-047907

- Prepublication history and additional supplemental material for this paper are available online. To view these files, please visit the journal online (http://dx.doi.org/10.1136/ bmjopen-2020-047907).

Received 11 December 2020 Accepted 09 December 2021

Check for updates

(C) Author(s) (or their employer(s)) 2022. Re-use permitted under CC BY-NC. No commercial re-use. See rights and permissions. Published by BMJ.

For numbered affiliations see end of article.

Correspondence to

Dr Jan Hau Lee;

lee.jan.hau@singhealth.com.sg

Judith Ju Ming Wong (D) ,1,2 Jacqueline Soo May Ong, ${ }^{3}$ Chengsi Ong, ${ }^{4}$ John Carsen Allen, ${ }^{2}$ Mihir Gandhi, ${ }^{5,6}$ Lijia Fan, ${ }^{3}$ Ryan Taylor, ${ }^{3}$ Joel Kian Boon Lim, ${ }^{1}$ Pei Fen Poh, ${ }^{1}$ Fang Kuan Chiou, ${ }^{7}$ Jan Hau Lee (D) ${ }^{1,2}$

\section{ABSTRACT}

Introduction Protein-energy malnutrition, increased catabolism and inadequate nutritional support leads to loss of lean body mass with muscle wasting and delayed recovery in critical illness. However, there remains clinical equipoise regarding the risks and benefits of protein supplementation. This pilot trial will determine the feasibility of performing a larger multicentre trial to determine if a strategy of protein supplementation in critically ill children with body mass index (BMI) z-score $\leq-2$ is superior to standard enteral nutrition in reducing the length of stay in the paediatric intensive care unit (PICU).

Methods and analysis This is a randomised controlled trial of 70 children in two PICUs in Singapore. Children with BMI z-score $\leq-2$ on PICU admission, who are expected to require invasive mechanical ventilation for more than 48 hours, will be randomised (1:1 allocation) to protein supplementation of $\geq 1.5 \mathrm{~g} / \mathrm{kg} /$ day in addition to standard nutrition, or standard nutrition alone for 7 days after enrolment or until PICU discharge, whichever is earlier. Feasibility outcomes for the trial include effective screening, satisfactory enrolment rate, timely protocol implementation (within first 72 hours) and protocol adherence. Secondary outcomes include mortality, PICU length of stay, muscle mass, anthropometric measurements and functional outcomes.

Ethics and dissemination The trial protocol was approved by the institutional review board of both participating centres (Singhealth Centralised Institutional Review Board and National Healthcare Group Domain Specific Review Board) under the reference number 2020/2742. Findings of the trial will be disseminated through peer-reviewed journals and scientific conferences. Trial registration number NCT04565613.

\section{INTRODUCTION}

\section{Background and rationale}

Paediatric malnutrition is defined as an imbalance between nutrient requirement and intake resulting in cumulative deficits of energy, protein or micronutrients. ${ }^{1}$ Malnutrition is pervasive in paediatric intensive care

\section{Strengths and limitations of this study}

- To our knowledge, this is the first randomised controlled trial applying enteral protein supplementation to critically ill children.

- There is no consensus on the optimal dose for protein intake during paediatric critical illness. Following recommendations of the American Society of Parenteral and Enteral Nutrition, this study will administer $1.5 \mathrm{~g} / \mathrm{kg} /$ day of protein to critically ill children. We chose to focus our study on nutritionally high-risk patients (body mass index (BMI) z-score $\leq-2)$ who have the greatest potential to benefit from nutritional therapy.

- As the distribution of malnourished children (as defined by a BMI z-score $\leq-2$ ) and paediatric intensive care unit support/therapies are variable geographically, the study will employ randomisation by centre to achieve balance in treatment allocation within each centre and account for centre-specific effects in the analysis.

unit (PICU) patients with a prevalence of approximately $18 \%-24 \%$ across the world. ${ }^{2-4}$ Protein malnutrition is caused by insufficient intake or proper utilisation of energy and protein leading to increased protein catabolism and was shown to occur in up to $40 \%$ of critically ill children. ${ }^{5-7}$ Increased catabolism of protein is likely attributable to a combination of various factors including critical illness inflammation, immobility and inadequate nutrition support. ${ }^{8}$ Inadequate nutritional provision has been reported in several PICU studies, with reported rates of protein inadequacy ranging from $37 \%$ to $87 \% .{ }^{9-11}$ Inadequate protein intake is associated with poor clinical outcomes in critically ill children. In a large, multicentre cohort study, protein intake $\leq 60 \%$ of the prescribed amount was associated with greater odds of mortality compared with those that received $>60 \%$ of 
prescribed protein. ${ }^{10}$ This was also demonstrated in critically ill children with acute respiratory distress syndrome requiring mechanical ventilation (MV) where children with protein intake of at least $1.5 \mathrm{~g} / \mathrm{kg} /$ day by day 3 of PICU stay had lower risk of mortality. ${ }^{9}$ Other concerns of inadequate protein include the loss of lean body mass with muscle wasting and subsequent functional disability, delayed MV weaning, prolonged hospital stay and increased mortality. ${ }^{12} 13$

There is marked heterogeneity of patients admitted to the PICU. One subset of patients shown to be at high risk of increased morbidity and mortality are those who are underweight on PICU admission. ${ }^{2}{ }^{14}$ It is hypothesised that children who are underweight have reduced body stores and are thus at greater risk of nutritional decline in the event of nutrient inadequacy. ${ }^{14}$ As such, a targeted approach of protein supplementation in this particular group of patients can potentially lead to improved clinical outcomes. Thus far, there are no trials evaluating the benefits/risks of supplemental enteral protein administration to critically ill children, highlighting the presence of clinical equipoise.

Due to the inherent challenges of completing randomised controlled trials (RCTs) in paediatric critical care, a rigorous pilot RCT is crucial to evaluate the feasibility of a large RCT. A pilot trial may prevent pursuit of a trial that is ultimately not feasible. This pilot trial is a step towards the large trial needed to provide high-quality, compelling evidence required to develop guidelines for nutrition care in the PICU.

\section{Objectives}

The objectives of this pilot trial are to determine the feasibility, efficacy and safety of conducting a large multicentre RCT on protein supplementation in critically ill children. Feasibility-related objectives include determination of the proportion of eligible patients approached for consent, likelihood of participants receiving their first protein supplementation within 72 hours of enrolment, participant accrual and protocol adherence. Since this is a pilot trial, efficacy objectives are secondary and will include a reduction in PICU mortality, length of stay and an improvement in muscle mass, anthropometric measures and functional status at predetermined follow-up intervals. Safety objectives include surveillance for adverse effects of protein supplementation-including feed intolerance, acute kidney injury, enterocolitis and other gastrointestinal-related complications. This pilot trial will also refine inclusion and exclusion criteria, test study procedures, streamline data collection and assess parental and physician acceptance of the proposed study design.

\section{METHODS AND ANALYSIS}

This protocol was written in accordance with the Standard Protocol Items: Recommendations for Interventional Trials guidelines and is summarised in table 1.

\section{Design and setting}

The study is a dual-centre open-label pilot RCT. It is an interventional study with two arms-protein supplementation and standard nutrition. The study is designed with a reasonable sample size to determine feasibility; study procedures are embedded into routine clinical care and will be executed by clinical personnel. Aside from the study intervention, the clinical diagnosis and management of study participants will be at the discretion of the PICU clinicians. Dietitians, who are study team members in the two centres, will be involved in the trial design and reviewing the nutrition plan of all trial participants

Clinical research coordinators (Monday to Friday) or study team members (Weekends and Public Holiday) will screen all children daily and maintain screening logs, including reasons for exclusion and reasons why parents of eligible children were not approached for consent.

\section{Study sites and period}

This pilot RCT will be conducted in the PICUs at KK Women's and Children's Hospital and the National University Hospital Singapore, two tertiary university affiliated paediatric centres in Singapore. The two centres have different existing nutrition practices, and performing the study procedures in these two centres will make the results more generalisable beyond a few centres with specialised nutritional teams. Should this pilot study be successful, a larger trial will be planned with involvement of other PICUs within the Pediatric Acute \& Critical Care Medicine Asian Network.

\section{Study participants}

Children with BMI z-score $\leq-2$ on PICU admission and who are anticipated to remain in the PICU long enough to benefit from protein supplementation will be considered for enrolment. Eligible children may be enrolled in this trial within 48 hours of starting feeds, provided feeding is started within the first 7 days of PICU admission. We chose to limit enrolment based on the timing commencement of feeds because we hypothesise that early rather than delayed protein supplementation is important in modulating clinical outcomes. It is anticipated that children need to be exposed to the intervention for 5-7 days to accrue any potential benefit or to experience potential harms. The inclusion and exclusion criteria are summarised in table 2. Children enrolled in a potentially confounding trial with biological interaction affecting outcome measures or adverse events will be excluded. However, if there are no identifiable biological interactions, the study team may consider co-enrolment in both trials.

\section{Patient and public involvement}

Patients and the public were not involved in the design of this protocol.

\section{Risks, adverse events and consent}

The potential for adverse events (AE) resulting from the proposed protein supplementation is expected to 


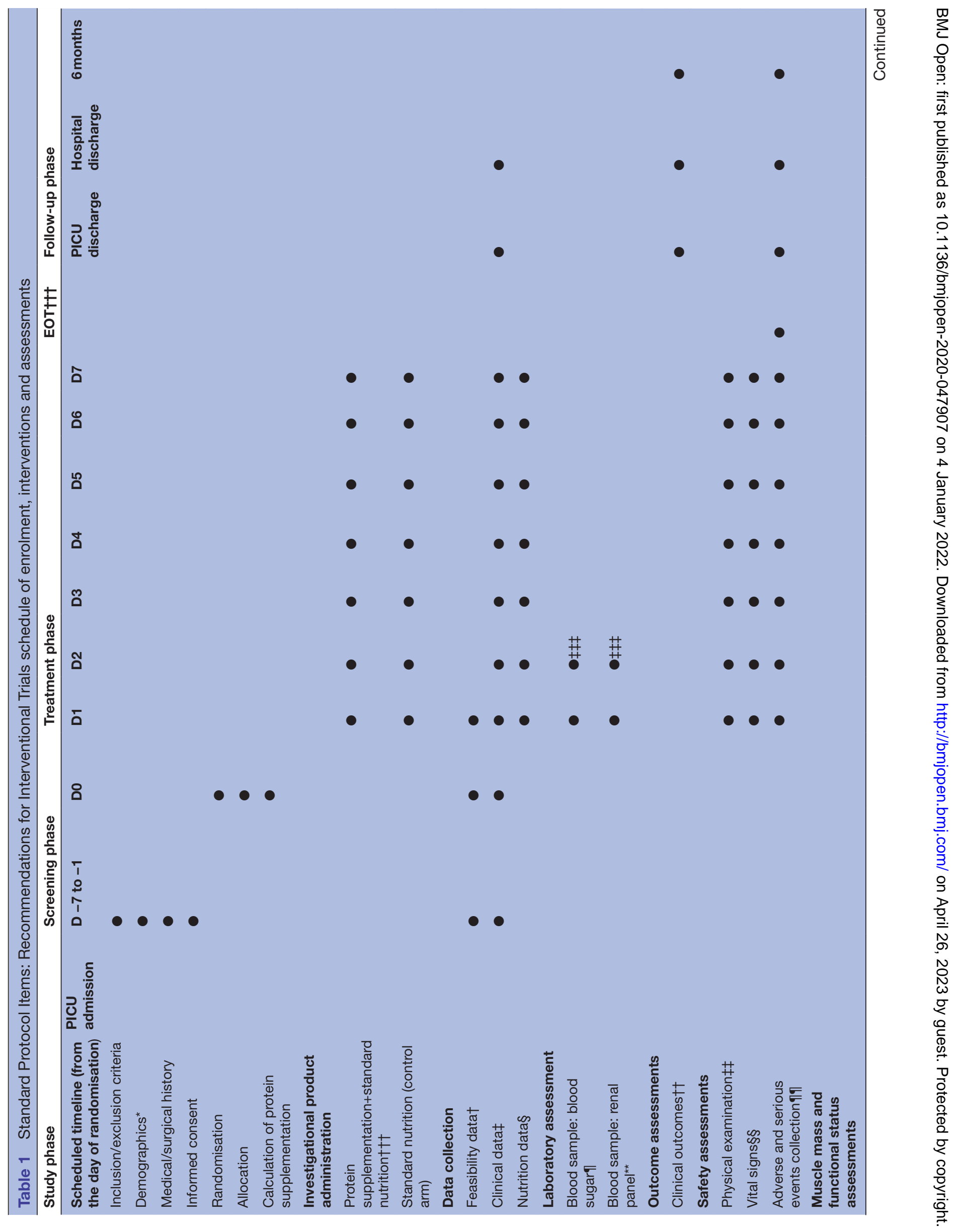




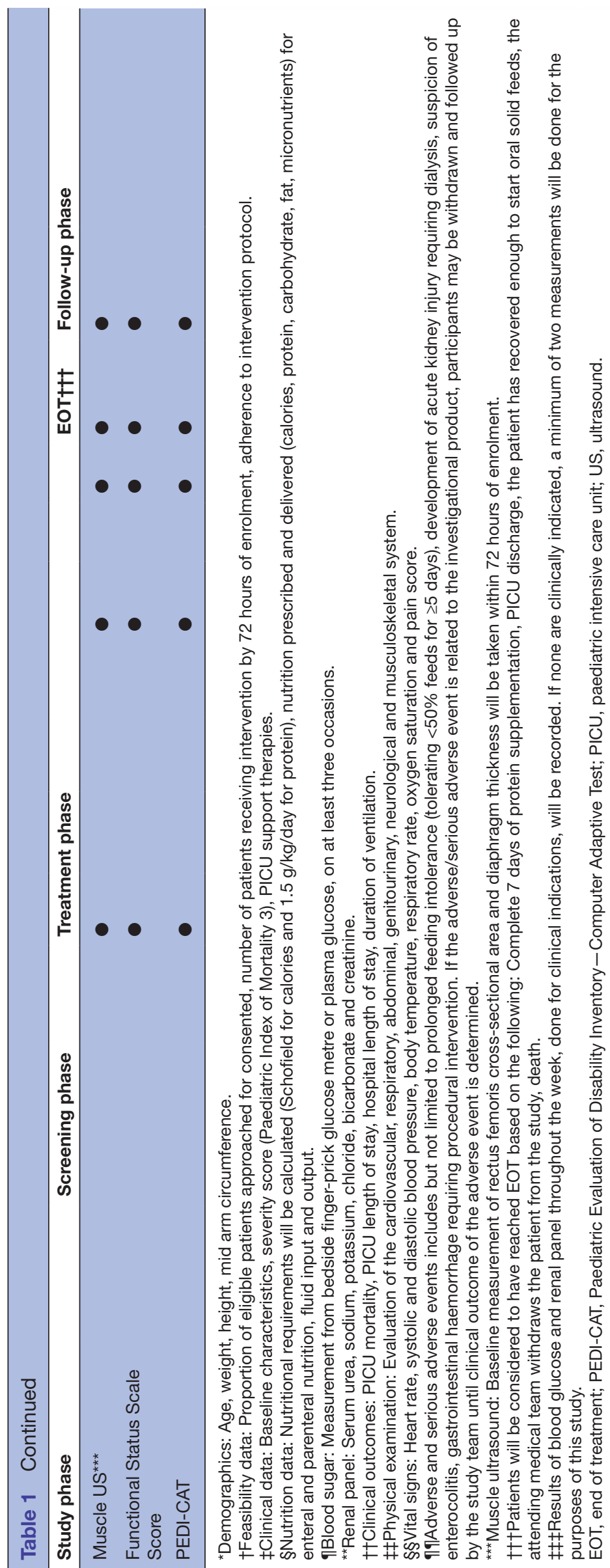


Table 2 Inclusion and exclusion criteria

$\begin{array}{ll}\text { Inclusion criteria } & \text { Children (28 days to } 18 \text { years of age) } \\ & \text { Both elective or emergency admissions } \\ & \text { BMI z-score } \leq-2 \text { on PICU admission } \\ & \text { Invasive MV beginning within } 48 \text { hours of PICU admission and anticipated to continue for } \geq 48 \text { hours } \\ & \text { Enteral nutrition support for feeding (eg, orogastric, nasogastric, gastrostomy, nasojejunal, orojejunal) }\end{array}$

\begin{tabular}{|c|c|}
\hline \multirow[t]{7}{*}{ Exclusion criteria } & $\begin{array}{l}\text { Contraindications to enteral nutrition (eg, gut haemorrhage, post-gastrointestinal surgery, necrotising } \\
\text { enterocolitis, ischaemic bowel) }\end{array}$ \\
\hline & Cow's milk protein allergy ${ }^{*}$ \\
\hline & Premature infants (corrected gestational age of $<44$ weeks) \\
\hline & Parenteral nutrition \\
\hline & $\begin{array}{l}\text { Progressive neuromuscular disease (eg, spinal muscular atrophy, Duchenne or other muscular dystrophy, } \\
\text { multiple sclerosis, amyotrophic lateral sclerosis) }\end{array}$ \\
\hline & $\begin{array}{l}\text { Medical conditions where increased or decreased protein intake is required, including acute kidney injury (stage } \\
3 \mathrm{KDIGO} \text { criteria), chronic kidney disease (stages } 4 \text { and 5), inborn errors of metabolism, fulminant liver failure, } \\
\text { severe burn injury }\end{array}$ \\
\hline & Enrolled in a potentially confounding trial \\
\hline
\end{tabular}

${ }^{*}$ The protein supplement used in our study, as well as, most standard polymeric formulas are contraindicated in patients with cow's milk protein allergy.

BMI, body mass index; KDIGO, Kidney Disease Improving Global Outcomes; MV, mechanical ventilation; PICU, paediatric intensive care unit.

be minimal as the amount is within the current recommendations of current guidelines, although based on low-quality evidence. ${ }^{15}$ Additionally, the design of this trial will seek to protect participants from harm by careful participant selection and appropriate monitoring. We will exclude children at highest risk for adverse effects. Extensive monitoring within the PICU will allow detection and treatment of any $\mathrm{AE}$ that do occur including refeeding syndrome.

Monitoring and reporting of AEs and serious AEs (SAEs) will be carried out in accordance with good clinical practice guidelines. Critically ill patients are inherently at high risk of SAE and the usual approach of reporting all SAEs to the respective ethical boards would result in large numbers of reported events not related to the trial intervention, but rather reflect the underlying disease process or expected complications of critical illness. ${ }^{16}$ The most likely AEs associated with the study interventions are the development of feed intolerance and diarrhoea, both of which are captured as outcomes and thus will not be reported as SAEs. Only SAEs that might reasonably be judged to be a consequence of participation in the trial and not due to the underlying disease or expected complications of critical illness, will be reported to the ethics boards. SAEs reporting will be performed within
24 hours to the reviewing ethical board and the data and safety monitoring board.

Participants may be withdrawn from the study at any time due to an AE or SAE. These will be followed-up by the study team until the clinical outcome from the $\mathrm{AE}$ is determined. Examples include:

- Prolonged feeding intolerance: Tolerating less than $50 \%$ of feeds prescribed over a period of $\geq 5$ days

- Development of acute kidney injury (according to Kidney Disease Improving Global Outcomes criteria) requiring dialysis ${ }^{17}$

- Suspicion of enterocolitis

- Significant gastrointestinal bleed requiring consideration for procedural intervention

- On request by treating primary physicians

Research staff will approach the child's parents or legal guardians for consent to enrol in this trial (online supplemental appendix 1: Patient consent form). Potential benefits and risks will be written in the informed consent document. Patients and parents will be informed of the purpose, intervention, benefits and possible risks of the study. Whenever possible, assent will be obtained from children above 6 years old when the patient has emerged from a critical illness state. 


\section{Randomisation, allocation concealment and blinding}

Participants will be randomised to protein supplementation or standard care in a 1:1 ratio, in undisclosed block size by sealed opaque envelopes, using a computer generated, centrally prepared allocation schedule by the study's biostatistics team. This randomisation will be stratified according to centre. Clinical research coordinators or study team members will approach eligible patients for consent. Only after consent is obtained, will the study team assign participants to allocated interventions-a model of prior consent will be adopted for this study.

All clinicians, bedside staff and research staff involved in clinical management of the participants, parents and guardians will be unblinded to the treatment allocation.

\section{Study interventions}

This trial is an interventional study with two arms. Participants will be randomised to enteral protein supplementation or no enteral protein supplementation (ie, standard nutrition care). For both trial arms, participants will be provided with enteral nutrition (EN) as per standard of care in each centre. General principles of the provision for EN using polymeric formula will include a stepwise progression of feeding volume individualised to the patient's weight, age and clinical status with close monitoring of tolerance by the nurses. Provision of EN values will be verified against nutritional requirements calculated by the dietitian. Children in both arms of the study will be fed so that the final feed volume will meet target energy requirements as calculated using the Schofield equation, with adjustments according to dietitian's assessment. ${ }^{15} \mathrm{~A} 10 \%$ variation in energy intake per day will be allowed in both arms for ease of preparation of feeds. ${ }^{18}$ Should feeding interruptions occur within either group due to clinical care, these will not be considered protocol violations.

Protein supplementation will be administered enterally and continue for a total of 7 days from study enrolment or until PICU discharge, whichever occurs earlier. Protein supplementation will consist of $100 \%$ whey protein isolate (Beneprotein, Nestle, Vevey, Switzerland). Protein supplementation will be provided in divided doses throughout the day and added to the prescribed milk formula feed regime to ensure a total protein intake of $1.5 \mathrm{~g} / \mathrm{kg} /$ day when full feeds are achieved. For example, a child with a weight of $25 \mathrm{~kg}$ receiving standard polymeric formula, would have an approximate intake of $40 \mathrm{kcal} / \mathrm{kg} /$ day and $1.2 \mathrm{~g} / \mathrm{kg} /$ day protein. An additional $7.5 \mathrm{~g}$ of protein is required, which is approximately equal to 1.25 scoops of protein supplement per day. Should a patient be prescribed with less than full feeds on a certain day (ie, as feeds are graded up), protein supplementation will be proportionately administered.

If a recovering patient is able to take per oral solid feeds during the study intervention period, the intervention will be suspended due to the variability of oral dietary intake and difficulty in estimating protein and energy intake. If, however, a recovering patient no longer requires assisted enteral feeding but continues to take per oral liquid/milk feeds, the intervention will continue until the stipulated time frame. The study intervention will be stopped if the attending medical team believes withdrawal of the participant from the study is critical. At this stage, the treating team can follow their usual practice with respect to nutrition provision. Parents may also withdraw their child from the study at any point for any reason-should this occur, only data collected up to the point of withdrawal will be used in the analysis.

\section{Data collection and management}

Data collected will include baseline characteristics, PICU support therapies and detailed nutrition data (table 1). The collection of nutrition data is a key component of this pilot study. Data pertaining to nutritional intakes of the participants will be collected. These include the following:

- Independent dietician estimation of energy (eg, Schofield equation) and protein requirement

- EN volume delivered and corresponding calories and protein received

- Highest and lowest glucose levels in the first 24 hours and first week of PICU admission

- Daily fluid balance and electrolytes (if daily laboratory investigations are not clinically indicated, a minimum of two measurements will be done for the purposes of this study)

Data will be extracted from electronic medical records by research staff who will enter the data directly into a secure web application (Research Electronic Data Capture (REDCap)) hosted by Singapore Clinical Research Institute (SCRI) ${ }^{19}$ The database will include both range checks and logic checks and will alert users to any missing data. The database will be stored at SCRI on a secure, firewall protected server with regular backups. Data can be entered by designated and trained users or survey respondents from any computer with an internet connection. User accounts incorporate electronic signatures comprised of a username and password. An audit trail is generated for all activity within each REDCap project.

\section{Study outcomes}

The pilot trial will focus on four primary feasibility outcomes and secondary clinical outcomes (table 3). Change in muscle size and anthropometry will be measured in relation to measurements performed within 24 hours of PICU admission (baseline) as an exploratory outcome. Ultrasonography will be used to visualise and capture muscle changes in critically ill children (online supplemental appendix 2) ${ }^{20}$ Change in functional status, as defined by the functional status scores (FSS) will be measured in relation to the premorbid function, and will be obtained from caregiver reports (online supplemental appendix 2). ${ }^{21}$

\section{Sample size and interim analysis}

The purpose of this pilot study is to investigate whether protein supplementation has promising efficacy and is 
Table 3 Study outcomes

Primary feasibility outcomes

Proportion of eligible patients approached for consent

Proportion of participants receiving their first protein supplementation within 72 hours of enrolment

Participant accrual, defined as an average monthly enrolment of at least one participant per centre

Protocol adherence, defined as $>80 \%$ of protein target administered according to the protocol in the intervention arm

$\begin{array}{ll}\text { Secondary clinical } & \text { PICU mortality } \\ \text { outcomes } & \text { PICU LOS } \\ \text { 28-day PICU-free days } & \text { Hospital LOS } \\ \text { MV duration } & \text { 28-day ventilator-free days } \\ \text { Development of AEs including feeding intolerance, diarrhoea, GI bleeding, and treatment used for GI bleeding } \\ \text { Change in muscle size (eg, ultrasound guided cross-sectional area of the rectus femoris, diaphragm } \\ \text { thickness) during PICU stay, at PICU discharge, hospital discharge and } 6 \text { months later } \\ \text { Change in anthropometric measurements (height, weight, BMI) at PICU discharge, hospital discharge and } 6 \\ \text { months later } \\ \text { Change in functional status (PEDI-CAT score, FSS score, hand-grip strength and 6-minute walk test) at } \\ \text { hospital discharge and } 6 \text { months later }\end{array}$

AE, adverse effects; BMI, body mass index; FSS, Functional Status Score; GI, gastrointestinal; LOS, length of stay; MV, mechanical ventilation; PEDI-CAT, Paediatric Evaluation of Disability Inventory-Computer Adaptive Test; PICU, paediatric intensive care unit.

worth further investigation. A large randomised study with usual care as the active control would be inappropriate as insufficient evidence of benefit of protein supplementation exists to justify such a study. In circumstances involving uncertainty of benefit and need for parsimony in resource expenditures, a small randomised study invoking the 'selection theory' approach proposed by Simon $e t a l^{22}{ }^{23}$ can provide an initial assessment of benefit. In the selection theory approach, the objective is to rank multiple potential treatments and then select those with the best responses for further study. However, our study involves only two treatments-protein supplementation versus standard feeds-which simplifies the approach in a determination of whether protein supplementation is better than standard feeds.

In the absence of any prior rates of clinical outcomes or effect size, our study will allow a response assessment and the potential for demonstrating greater efficacy of protein supplementation versus standard feeds in underweight critically ill children, with high statistical power, using a procedure that circumvents a formal hypothesis test.

Effect size is defined as $\delta=\left(\mu_{1}-\mu_{2}\right) / \sigma$, where $\mu_{1}$ and $\mu_{2}$ represent clinical endpoint population means for the protein supplementation and standard feeds arms, respectively. In calculating sample size in the context of selection theory, we postulate the conventional underlying null and alternative hypotheses of $\mathrm{H}_{0}$ : $\delta \leq 0$ versus $\mathrm{H}_{1}$ : $\delta>0$, respectively. In our pilot study, we will target an effect size of $\delta=0.33$, which is considered a small-to-moderate effect size and often viewed as representing a clinically important difference. ${ }^{24}$ If protein supplementation is superior to standard feeds by $\delta \geq 0.33$, we desire to detect this difference with power $\geq 90 \%$. However, under a true null hypothesis, we will choose to ignore the type I error rate, and so set $\alpha=50 \%$ - equivalent to random chance. Performing the sample size calculation based on a onesided hypothesis test of two independent means using a two-sample t-test with one-sided $\alpha=0.50$, a sample size of $\mathrm{n}=35$ per group achieves power $=0.92$ to detect an effect size of $\delta=0.33$. (PASS commercial software was used to perform the sample size calculation.)

From our preliminary data, we expect to have approximately 48 patients per year meet eligibility criteria for our pilot study. Our projection is that we will see 144 eligible patients over the 3-year recruitment period $(3 \times 48)$. Assuming a conservative consent rate of $55 \%$, we anticipate at least 80 patients with BMI z-score $\leq-2$ which will provide 40 patients in each study arm. Accounting for a dropout rate of $10 \%-12 \%$ due to mortality and other causes, we would anticipate $\mathrm{n}=35$ patients per arm completing the study (total $\mathrm{N}=70$ ), which for $\delta \geq 0.33$ achieves $>90 \%$ probability for demonstrating superiority of protein supplementation to standard feeds. To ensure we are able to assess feasibility and test study procedures and infrastructure at each site, we aim to enrol 26 or 27 patients per centre per year (13 or 14 per arm).

It is emphasised that under the selection theory paradigm, the best treatment for further consideration in a subsequent larger trial is selected on the basis of descriptive statistics-in this case, higher mean value. Hence, given an effect size of $\delta \geq 0.33$, the proposed procedure and sample size will ensure a $>90 \%$ probability of protein supplementation as the better treatment, demonstrated by a higher mean value, without a formal hypothesis test. A 95\% CI will be calculated on the protein supplementation 


\section{Completion of pilot trial}

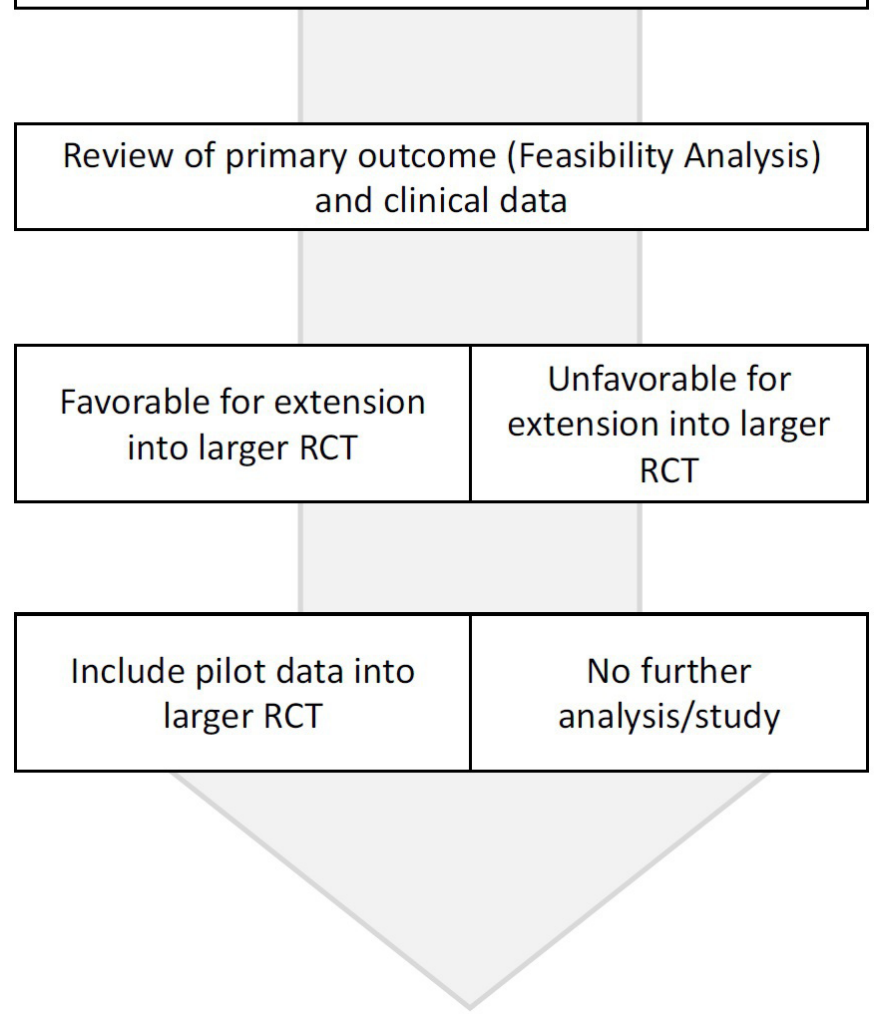

Figure 1 Flowchart for analytical approach of pilot trial. RCT, randomised controlled trial.

versus standard feeds mean difference for the clinical efficacy variables.

Should recruitment be slow and challenging, the study team will meet and decide on the best method in increasing enrolment. Some a priori strategies that we will consider include (but not limited to) changing the criteria to include:

- Children on non-invasive ventilation or respiratory distress, and requiring any form of tube feeding

- Children with BMI $\leq-1$ on PICU admission

\section{Statistical analysis}

All analyses will be performed using an intention-to-treat principle. There will be no interim efficacy analyses for this pilot trial. If, after the completion of the pilot trial, the study team determines that there are no important changes to the inclusion and exclusion criteria, the results will not be unblinded for the clinical outcomes of the pilot trial (figure 1). Instead, we will report the feasibility outcomes, present the clinical outcomes as a single cohort and consider the pilot trial to be an internal pilot, meaning that we will include the pilot trial patients in the larger RCT. If the study team determines a large trial is not feasible or if including the pilot trial patients in the larger RCT is inappropriate, the clinical outcomes and group comparisons will be reported so that the trial can be included in future meta-analyses. We will use the
Consolidated Standards of Reporting Trials guidelines for reporting. ${ }^{25} 26$

\section{Feasibility analysis}

Feasibility will be demonstrated by (1) achieving recruitment targets (effective screening, timely enrolment and satisfactory participant accrual), (2) demonstrating at least $80 \%$ regimen compliance to allocated groups, (3) demonstrating safety of the intervention and (4) demonstrating delivery of protein with a separation of at least a $0.5 \mathrm{~g} / \mathrm{kg} /$ day in the intervention and control arms. Effective screening will be achieved if $90 \%$ of all PICU admissions are screened within 24 hours, timely enrolment will be achieved if $90 \%$ of all eligible participants are enrolled within 48 hours of meeting eligibility criteria and satisfactory participant accrual is considered if both centres recruit a total of at least 26 patients per year. For the feasibility outcomes we will report the proportions of children meeting each criterion and the associated $95 \%$ CIs. We will also compare total protein received by participants in the groups. We chose a separation of $0.5 \mathrm{~g} / \mathrm{kg} /$ day protein as clinically meaningful based on our data from two cohorts of critically ill patients (bronchiolitis ${ }^{27}$ and acute respiratory distress syndrome ${ }^{9}$ ) which demonstrated that without supplementation, the median protein achieved within the first 3 days of illness was $<1.0 \mathrm{~g} / \mathrm{kg} /$ day and that $0.5 \mathrm{~g} / \mathrm{kg} /$ day separation was associated with improved clinical outcomes, respectively. The number of participants who consented (or not) and completed (or discontinued early) the study and the reasons for non-consent/discontinuation will be summarised using counts and percentages. Demographic (eg, race, age, gender) and baseline clinical characteristics will also be summarised using descriptive statistics.

\section{Clinical outcome analysis}

PICU and hospital mortality rate in each arm and differences between the protein supplementation and standard of care arms will be presented with exact $95 \%$ CIs. Medians of continuous variables (PICU length of stay (LOS), hospital LOS, MV duration, 28-day ventilator-free days (VFD) and PICU-free days (IFD)) will be presented along with corresponding 95\% CIs. LOS and duration endpoints will be compared between treatment groups using a log-rank test in conjunction with Kaplan-Meier survival curves. Patients who die within 28 days will be censored. If warranted, additional analysis using Cox regression will be performed to adjust for the influence of potential demographic and clinical confounders

Differences in total hospital LOS, PICU LOS, duration of MV, VFD and IFD observed in the protein supplementation group relative to the standard care group will be assessed by subgroup according to illness severity level as characterised by Paediatric Index of Mortality 3 scores. ${ }^{28}{ }^{29}$ Change in muscle size (eg, ultrasound guided cross-sectional area of the rectus femoris), anthropometry (height, weight, BMI) and functional status (Paediatric Evaluation of Disability Inventory-Computer Adaptive 
Test score, FSS score, hand-grip strength and 6-minute walk test) during PICU stay, at PICU discharge, hospital discharge and 6 months later will also be measured as exploratory outcomes.

\section{Handling of missing data}

Baseline characteristics, PICU support therapies, nutrition and outcome data are routinely recorded for all patients in the electronic medical record system. Therefore, data is very unlikely to be missing. Trained clinical research coordinators will enter data into the REDCap system which will have both range checks and logic checks and alert users to any missing data. If data are still missing, no imputation will be done.

\section{Trial steering committee}

There will be a single steering committee overseeing trial execution over the two participating sites. The committee will consist of the two site-principal investigators, two dietitians, two nursing leads and four study team members representative from both sites. This group will be responsible for each step of the trial process including ensuring consistent screening, reviewing recruitment numbers, deliberating on eligibility of participants and adverse events. The steering committee will meet quarterly to discuss progress of the trial and troubleshoot any problems or delays in the project plan.

\section{Data safety monitoring}

An independent Data Safety Monitoring Committee (DSMC) comprised of three members with experience and expertise in methods, statistics and critical care collectively will monitor the progress and safety of the trial. The DSMC will meet and review the available data when $30 \%$ of randomised patients (total of 20 patients or at least 10 in each arm) have completed 1 month of follow-up. Additional meetings may be held at the discretion of the Chair of the DSMC. The committee will receive SAE reports as they occur. All data will be presented to the DSMC tabulated by intervention group, but the members will remain blinded to the actual group assignment. The committee will review SAEs and centre performance (enrolment, data quality and protocol adherence) and any pertinent external data such as newly published studies or other potentially relevant safety information. They may recommend early termination of the trial if there are SAEs associated with the trial intervention, but no formal stopping rules will be used: this decision will be based on clinical judgement of the DSMC. The DSMC will keep all trial data, committee deliberations and meeting minutes confidential until the end of the trial.

\section{DISCUSSION}

Though primarily designed to assess feasibility, this study will be the first RCT investigating the benefits/risks of protein supplementation in addition to standard nutrition in critically ill children. Continuation of this pilot trial into the definitive multicentre RCT will address an important scientific hypothesis-does early enteral protein supplementation of $1.5 \mathrm{~g} / \mathrm{kg} /$ day improve clinical, functional and nutritional outcomes in critically ill children. Numerous prior observational studies with similar aims ${ }^{59}$ were inadequately controlled for important selection biases, that is, sicker patients selectively received less nutrition (including less protein). As such, drawing a conclusion that higher nutrition (including higher protein) intake is associated with improved outcomes is inherently biased. A randomised design, such as the proposed study, is the only way to control for such bias.

In critical illness (eg, sepsis, major surgery), changes in endocrine-metabolic responses lead to an imbalance in protein synthesis and degradation. ${ }^{30}$ A negative protein balance is associated with immunosuppression, poor wound healing, loss of lean muscle mass and a delay in the recovery process. ${ }^{31}$ Muscle catabolism is inevitable in acute illness and its intensity depends on the severity of illness. ${ }^{30}$ With exogenous nutritional protein and sufficient energy intake, it is postulated that lean muscle mass can be diverted away from oxidative metabolic pathways and preserved. ${ }^{32}$ It is, however, unknown what constitutes the optimal amount of protein required to minimise loss of lean muscle mass and the optimal timing of administration in relation to critical illness. Prevailing data from adult studies demonstrate benefits (improved muscle mass ${ }^{33}$ reduced mortality ${ }^{34}$ ), as well as, harm (muscle wasting, ${ }^{12}$ increased mortality ${ }^{36}$ ) associated with protein intake in critical illness. These adult data cannot be extrapolated to children, whose protein and energy requirements are inherently different. ${ }^{37}$

There are currently several recommendations for protein requirements during critical illness. The 2018 European Society for Clinical Nutrition and Metabolism guidelines recommends $1.3 \mathrm{~g} / \mathrm{kg} /$ day protein equivalents be delivered in critically ill adults. ${ }^{38}$ In contrast, the American Society for Parenteral and Enteral Nutrition (ASPEN) in conjunction with the Society of Critical Care Medicine 2016 guidelines for critically ill adults recommends $1.2-2.0 \mathrm{~g} / \mathrm{kg} /$ day of protein intake. ${ }^{39}$ In critically ill children the recommended protein requirement according to the ASPEN 2017 guidelines was $1.5 \mathrm{~g} / \mathrm{kg} /$ day, acknowledging that the optimal protein intake required to attain a positive protein balance may be much higher than this minimum threshold. ${ }^{15}$ It was also suggested that provision of protein early in the course of critical illness was desirable to promote positive nitrogen balance. ${ }^{15}$ The provision of $1.5 \mathrm{~g} / \mathrm{kg} /$ day of enteral protein in our intervention arm is based on these guidelines and on translational studies indicating that at least $1.5 \mathrm{~g} / \mathrm{kg} /$ day of protein was required to equilibrate nitrogen and energy balances in critically ill children. ${ }^{40} 41$

It is noteworthy, however, that the PEPaNIC trial (early vs late parenteral nutrition in critically ill children) comparing nutrition supplementation in the form of early parenteral nutrition within 24 hours of PICU admission versus late supplementation with parenteral nutrition 
after the first week of PICU stay demonstrated a higher rate of new infection, prolonged PICU stay and decreased likelihood of being discharged alive from hospital in the early group. In the PEPaNIC trial, the early group received higher protein intake (approximately $1.5 \mathrm{~g} / \mathrm{kg}$ / day) in the form of an intravenous amino acid solution over the first week of PICU stay. ${ }^{42}$ There are, however, fundamental differences between the current proposed study and PEPaNIC trial which make direct extrapolation of outcomes inappropriate. First, the PEPaNIC trial included critically ill children 'at-risk of malnutrition' (using the Screening Tool for Risk on Nutritional Status and Growth (STRONGkids)), whereas, we chose to focus on established underweight patients (BMI z-score $\leq-2$ ) who have the greatest potential to benefit from nutritional therapy. ${ }^{43}$ Second, the PEPaNIC trial used parenteral nutrition instead of EN which in itself has been associated with infections and other poor outcomes. ${ }^{44-46}$ As such, an empirical trial of supplemental enteral protein is warranted and will be informative.

Despite the benefits of a randomised design, our pilot RCT may be susceptible to some potential bias. In this dual centre RCT, there is no standardised EN protocol between the two centres. We did not mandate application of a standardised EN protocol across both sides because we aim to scale up and conduct a larger pragmatic trial if feasibility is demonstrated. It will be challenging to perform a larger trial with a standardised EN protocol across multiple sites. Though routine protein supplementation is not currently practiced in both centres, the variable practice may lead to potential overlap in protein dosing between the intervention and control arms. We recognise this as a limitation but are unable to justify ethically to reduce protein intake of patients to below what standard care provides. In addition, a proportion of patients will be excluded from the study due to safety concerns (exclusion criteria) and this will limit the generalisability of this RCT. The pragmatic design of this study also allows the managing clinical team (including nurses and physicians) and investigators in charge of enrolling participants to be unblinded to the intervention. However, blinding will be maintained for all other research staff, such as statisticians. As indirect calorimetry is not readily available at both sites, energy equations would be used to calculate requirements, which could result in energy overfeeding or underfeeding. ${ }^{47}$ Non-protein calories which may in itself indirectly affect protein catabolism ${ }^{48}$ and clinical outcomes, ${ }^{35} 49$ will be recorded and analysed but will not be strictly controlled. Lastly, sedation practices, physical activity ${ }^{50}$ and early rehabilitation $^{52}$ (which are challenging to control) may interact with nutritional therapy to affect clinical, nutritional and functional outcomes measured in this study.

\section{Trial status}

This trial has obtained ethics approval and clinical trial registration. Patient recruitment is anticipated to begin on 4 January 2021 and to complete on 3 January 2024. Follow-up will be completed by 30 June 2024 .

\section{Author affiliations}

${ }^{1}$ Children's Intensive Care Unit, KK Women's and Children's Hospital, Singapore ${ }^{2}$ Duke-NUS Medical School, Singapore

${ }^{3}$ Division of Paediatric Critical Care, National University Hospital, Singapore

${ }^{4}$ Department of Dietetics, KK Women's and Children's Hospital, Singapore

${ }^{5}$ Singapore Clinical Research Institute, Singapore

${ }^{6}$ Tampere University, Tampere, Finland

${ }^{7}$ Gastroenterology, KK Women's and Children's Hospital, Singapore

Twitter Jan Hau Lee @leejanhau

Acknowledgements The authors would like to thank Ms. Kathy Liaw for her assistance in setting up and continued support in this trial.

Contributors JHL, JJ-MW, JSMO, CO, JCA and FKC conceived and designed this study. JHL, JCA and MG designed the statistical plan. JHL, JJ-MW, JSMO and CO obtained permission from the ethics committees. JHL, JJ-MW, JSMO, CO, JCA, FKC, LF, RT, JKBL and PFP will carry out this trial. JHL, JJ-MW, CO and JCA drafted this manuscript. JSM0, FKC, LF, RT, JKBL and PFP carefully reviewed the manuscript; and all authors read and approved the final manuscript.

Funding This work is supported by the National Medical Research Council, Ministry of Health, Singapore (MOH-TA19nov-0001).

Competing interests None declared.

Patient consent for publication Not applicable.

Provenance and peer review Not commissioned; externally peer reviewed.

Supplemental material This content has been supplied by the author(s). It has not been vetted by BMJ Publishing Group Limited (BMJ) and may not have been peer-reviewed. Any opinions or recommendations discussed are solely those of the author(s) and are not endorsed by BMJ. BMJ disclaims all liability and responsibility arising from any reliance placed on the content. Where the content includes any translated material, BMJ does not warrant the accuracy and reliability of the translations (including but not limited to local regulations, clinical guidelines, terminology, drug names and drug dosages), and is not responsible for any error and/or omissions arising from translation and adaptation or otherwise.

Open access This is an open access article distributed in accordance with the Creative Commons Attribution Non Commercial (CC BY-NC 4.0) license, which permits others to distribute, remix, adapt, build upon this work non-commercially, and license their derivative works on different terms, provided the original work is properly cited, appropriate credit is given, any changes made indicated, and the use is non-commercial. See: http://creativecommons.org/licenses/by-nc/4.0/.

\section{ORCID iDs}

Judith Ju Ming Wong http://orcid.org/0000-0002-7987-4303

Jan Hau Lee http://orcid.org/0000-0002-8430-4217

\section{REFERENCES}

1 Mehta NM, Corkins MR, Lyman B, et al. Defining pediatric malnutrition: a paradigm shift toward etiology-related definitions. JPEN J Parenter Enteral Nutr 2013;37:460-81.

2 Prince NJ, Brown KL, Mebrahtu TF, et al. Weight-for-age distribution and case-mix adjusted outcomes of 14,307 paediatric intensive care admissions. Intensive Care Med 2014;40:1132-9.

3 Pollack MM, Wiley JS, Kanter R, et al. Malnutrition in critically III infants and children. JPEN J Parenter Enteral Nutr 1982;6:20-4.

4 Hulst J, Joosten K, Zimmermann L, et al. Malnutrition in critically ill children: from admission to 6 months after discharge. Clin Nutr 2004;23:223-32.

5 Mehta NM, Bechard LJ, Cahill N, et al. Nutritional practices and their relationship to clinical outcomes in critically ill children-an international multicenter cohort study*. Crit Care Med 2012;40:2204-11.

6 Hulst JM, van Goudoever JB, Zimmermann LJI, et al. The effect of cumulative energy and protein deficiency on anthropometric parameters in a pediatric ICU population. Clin Nutr 2004;23:1381-9.

7 Coss-Bu JA, Hamilton-Reeves J, Patel JJ, et al. Protein requirements of the critically ill pediatric patient. Nutrition in Clinical Practice 2017;32:128S-41.

8 Chwals WJ. The Acute Metabolic Response to Injury in Children. In: PSGaMM M, ed. Pediatric critical care nutrition. 1 edn. United States: The McGraw-Hill Companies, 2015: 3-18. 
9 Wong JJ-M, Han WM, Sultana R, et al. Nutrition delivery affects outcomes in pediatric acute respiratory distress syndrome. JPEN $J$ Parenter Enteral Nutr 2017;41:1007-13

10 Mehta NM, Bechard LJ, Zurakowski D, et al. Adequate enteral protein intake is inversely associated with 60-d mortality in critically ill children: a multicenter, prospective, cohort study. Am J Clin Nutr 2015;102:199-206.

11 Melro EC, de Souza Lima AE, Missagia de Mattos Springer A, et al. Protein intake deficiency in critically ill children with respiratory insufficiency: a call to action? Clin Nutr ESPEN 2020;37:69-74.

12 Puthucheary ZA, Rawal J, McPhail M, et al. Acute skeletal muscle wasting in critical illness. JAMA 2013;310:1591-600.

13 Parry SM, El-Ansary D, Cartwright MS, et al. Ultrasonography in the intensive care setting can be used to detect changes in the quality and quantity of muscle and is related to muscle strength and function. J Crit Care 2015;30:1151.e9-1151.e14.

14 Bechard LJ, Duggan C, Touger-Decker R, et al. Nutritional status based on body mass index is associated with morbidity and mortality in mechanically ventilated critically ill children in the PICU. Crit Care Med 2016;44:1530-7.

15 Mehta NM, Skillman HE, Irving SY, et al. Guidelines for the provision and assessment of nutrition support therapy in the pediatric critically ill patient: Society of critical care medicine and American Society for parenteral and enteral nutrition. JPEN J Parenter Enteral Nutr 2017;41:706-42.

16 Cook D, Lauzier F, Rocha MG, et al. Serious adverse events in academic critical care research. CMAJ 2008;178:1181-4.

17 Levey AS, Eckardt K-U, Dorman NM, et al. Nomenclature for kidney function and disease: report of a kidney disease: improving global outcomes (KDIGO) consensus conference. Kidney Int 2020;97:1117-29.

18 Kerklaan D, Hulst JM, Verhoeven JJ, et al. Use of indirect calorimetry to detect overfeeding in critically ill children: finding the appropriate definition. J Pediatr Gastroenterol Nutr 2016;63:445-50

19 Institute SCR. Available: https://www.scri.edu.sg

20 Ong C, Lee JH, Leow MKS, et al. Skeletal Muscle Ultrasonography in Nutrition and Functional Outcome Assessment of Critically III Children: Experience and Insights From Pediatric Disease and Adult Critical Care Studies [Formula: see text]. JPEN J Parenter Enteral Nutr 2017;41:1091-9.

21 Pollack MM, Holubkov R, Glass $\mathrm{P}$, et al. Functional status scale: new pediatric outcome measure. Pediatrics 2009;124:e18-28.

22 Simon R, Wittes RE, Ellenberg SS. Randomized phase II clinical trials. Cancer Treat Rep 1985;69:1375-81.

23 Cohen J. Statistical power analysis for the behavioral sciences. New York: Routledge, 1988

24 Angst F, Aeschlimann A, Angst J. The minimal clinically important difference raised the significance of outcome effects above the statistical level, with methodological implications for future studies. $J$ Clin Epidemiol 2017;82:128-36.

25 Schulz KF, Altman DG, Moher D, et al. Consort 2010 statement: updated guidelines for reporting parallel group randomised trials. BMJ 2010;340:c332

26 Eldridge SM, Chan CL, Campbell MJ, et al. Consort 2010 statement: extension to randomised pilot and feasibility trials. Pilot Feasibility Stud 2016;2:64.

$27 \mathrm{Ng} \mathrm{GYH}$, Ong C, Wong JJM, et al. Nutritional status, intake, and outcomes in critically ill children with bronchiolitis. Pediatr Pulmonol 2020;55:1199-206.

28 Straney L, Clements A, Parslow RC, et al. Paediatric index of mortality 3: an updated model for predicting mortality in pediatric intensive care*. Pediatr Crit Care Med 2013;14:673-81.

29 Wong JJ, Hornik CP, Mok YH, et al. Performance of the paediatric index of mortality 3 and paediatric logistic organ dysfunction 2 scores in critically ill children. Ann Acad Med Singap 2018;47:285-90.

30 Elwyn $\mathrm{DH}$. Protein metabolism and requirements in the critically ill patient. Crit Care Clin 1987;3:57-69.
31 Plank LD, Connolly AB, Hill GL. Sequential changes in the metabolic response in severely septic patients during the first 23 days after the onset of peritonitis. Ann Surg 1998;228:146-58.

32 Wolfe RR, Goodenough RD, Burke JF, et al. Response of protein and urea kinetics in burn patients to different levels of protein intake. Ann Surg 1983;197:163-71.

33 Ferrie S, Allman-Farinelli M, Daley M, et al. Protein requirements in the critically ill: a randomized controlled trial using parenteral nutrition. JPEN J Parenter Enteral Nutr 2016;40:795-805.

34 Nicolo M, Heyland DK, Chittams J, et al. Clinical outcomes related to protein delivery in a critically ill population: a multicenter, multinational observation study. JPEN J Parenter Enteral Nutr 2016;40:45-51.

35 Allingstrup MJ, Esmailzadeh N, Wilkens Knudsen A, et al. Provision of protein and energy in relation to measured requirements in intensive care patients. Clin Nutr 2012;31:462-8.

36 Braunschweig CL, Freels S, Sheean PM, et al. Role of timing and dose of energy received in patients with acute lung injury on mortality in the intensive nutrition in acute lung injury trial (intact): a post hoc analysis. Am J Clin Nutr 2017;105:411-6.

37 Coss-Bu JA, Hamilton-Reeves J, Patel JJ, et al. Protein requirements of the critically ill pediatric patient. Nutr Clin Pract 2017;32:128S-41.

38 Singer P, Blaser AR, Berger MM, et al. ESPEN guideline on clinical nutrition in the intensive care unit. Clin Nutr 2019;38:48-79.

39 McClave SA, Taylor BE, Martindale RG, et al. Guidelines for the provision and assessment of nutrition support therapy in the adult critically ill patient. JPEN J Parenter Enteral Nutr 2016;40:159-211.

40 Jotterand Chaparro C, Laure Depeyre J, Longchamp D, et al. How much protein and energy are needed to equilibrate nitrogen and energy balances in ventilated critically ill children? Clin Nutr 2016;35:460-7.

41 Coss-Bu JA, Jefferson LS, Walding D, et al. Resting energy expenditure and nitrogen balance in critically ill pediatric patients on mechanical ventilation. Nutrition 1998;14:649-52.

42 Fivez T, Kerklaan D, Mesotten D, et al. Early versus late parenteral nutrition in critically ill children. $N$ Engl J Med Overseas Ed 2016;374:1111-22.

43 Compher C, Chittams J, Sammarco T, et al. Greater protein and energy intake may be associated with improved mortality in higher risk critically ill patients: a multicenter, multinational observational study. Crit Care Med 2017;45:156-63.

44 Braunschweig CL, Levy P, Sheean PM, et al. Enteral compared with parenteral nutrition: a meta-analysis. Am J Clin Nutr 2001;74:534-42.

45 Yeung CY, Lee HC, Huang FY. Sepsis during total parenteral nutrition: exploration of risk factors and determination of the effectiveness of peripherally inserted central venous catheters. Pediatr Infect Dis J 1998;17:135-42.

46 Zaloga GP. Parenteral nutrition in adult inpatients with functioning gastrointestinal tracts: assessment of outcomes. Lancet 2006;367:1101-11

47 Meyer R, Kulinskaya E, Briassoulis G, et al. The challenge of developing a new predictive formula to estimate energy requirements in ventilated critically ill children. Nutr Clin Pract 2012;27:669-76.

48 Kreymann G, DeLegge MH, Luft G, et al. The ratio of energy expenditure to nitrogen loss in diverse patient groups--a systematic review. Clin Nutr 2012;31:168-75.

49 Weijs PJM, Looijaard WGPM, Beishuizen A, et al. Early high protein intake is associated with low mortality and energy overfeeding with high mortality in non-septic mechanically ventilated critically ill patients. Crit Care 2014;18:701

50 Burtin C, Clerckx B, Robbeets C, et al. Early exercise in critically ill patients enhances short-term functional recovery. Crit Care Med 2009;37:2499-505

51 Schweickert WD, Pohlman MC, Pohlman AS, et al. Early physical and occupational therapy in mechanically ventilated, critically ill patients: a randomised controlled trial. Lancet 2009;373:1874-82.

52 Denehy L, Skinner EH, Edbrooke L, et al. Exercise rehabilitation for patients with critical illness: a randomized controlled trial with 12 months of follow-up. Crit Care 2013;17:R156. 